OPEN ACCESS

Edited by:

Yuji Morita,

Aichi Gakuin University, Japan

Reviewed by:

Pilar García,

Consejo Superior de Investigaciones

Cientificas, Spain

Meiying Yan,

National Institute for Communicable Disease Control and Prevention, China

Ronen Nissan Hazan,

Massachusetts General Hospital, USA

*Correspondence:

Peter-John Wormald

peterj.wormald@adelaide.edu.au

Received: 08 December 2016 Accepted: 08 February 2017

Published: 24 February 2017

Citation:

Drilling AJ, Ooi ML, Miljkovic D, James C, Speck P, Vreugde S, Clark J and Wormald P-J (2017) Long-Term

Safety of Topical Bacteriophage

Application to the Frontal Sinus

Region.

Front. Cell. Infect. Microbiol. 7:49. doi: 10.3389/fcimb.2017.00049

\section{Long-Term Safety of Topical Bacteriophage Application to the Frontal Sinus Region}

\author{
Amanda J. Drilling ${ }^{1}$, Mian L. Ooi ${ }^{1}$, Dijana Miljkovic ${ }^{1}$, Craig James ${ }^{2}$, Peter Speck ${ }^{3}$, \\ Sarah Vreugde ${ }^{1}$, Jason Clark ${ }^{4}$ and Peter-John Wormald ${ }^{1 *}$ \\ ${ }^{1}$ Department of Surgery-Otolaryngology Head and Neck Surgery, The University of Adelaide, Adelaide, SA, Australia, \\ ${ }^{2}$ Adelaide Pathology Partners, Adelaide, SA, Australia, ${ }^{3}$ School of Biological Sciences, Flinders University, Bedford Park, SA, \\ Australia, ${ }^{4}$ Fixed Phage Limited, Glasgow, UK
}

Background: Staphylococcus aureus biofilms contribute negatively to a number of chronic conditions, including chronic rhinosinusitis (CRS). With the inherent tolerance of biofilm-bound bacteria to antibiotics and the global problem of bacterial antibiotic resistance, the need to develop novel therapeutics is paramount. Phage therapy has previously shown promise in treating sinonasal $S$. aureus biofilms.

Methods: This study investigates the long term (20 days) safety of topical sinonasal flushes with bacteriophage suspensions. The bacteriophage cocktail NOV012 against S. aureus selected for this work contains two highly characterized and different phages, P68 and K710. Host range was assessed against $S$. aureus strains isolated from CRS patients using agar spot tests. NOV012 was applied topically to the frontal sinus region of sheep, twice daily for 20 days. General sheep wellbeing, mucosal structural changes and inflammatory load were assessed to determine safety of NOV012 application.

Results: NOV012 could lyse 52/61 (85\%) of a panel of locally derived CRS clinical isolates. Application of NOV012 to the frontal sinuses of sheep for 20 days was found to be safe, with no observed inflammatory infiltration or tissue damage within the sinus mucosa.

Conclusion: NOV012 cocktail appears safe to apply for extended periods to sheep sinuses and it could infect and lyse a wide range of $S$. aureus CRS clinical isolates. This indicates that phage therapy has strong potential as a treatment for chronic bacterial rhinosinusitis.

Keywords: bacteriophage, therapeutic safety, topical, inflammation, cilia, Staphylococcus aureus

\section{INTRODUCTION}

Staphylococcus aureus is an opportunistic bacterial pathogen forming biofilms, which are known to be involved in a number of infective chronic diseases (Petti and Fowler, 2003; Ziran, 2007; Baldoni et al., 2009; Foreman and Wormald, 2010; Singhal et al., 2010, 2011; Jervis-Bardy and Wormald, 2012). These include osteomyelitis (Ziran, 2007), endocarditis (Petti and Fowler, 2003), as well as infections of indwelling devices (Baldoni et al., 2009). In addition, sinonasal bound

Abbreviations: NOV012, Novolytics bacteriophage cocktail; Hip, Heat inactivated NOV012 bacteriophage cocktail; SEM, scanning electron microscopy; CRS, chronic rhinosinusitis. 
biofilms of $S$. aureus are known to impact negatively in chronic rhinosinusitis (CRS). The presence of such infections in CRS reportedly leads to more frequent out-patient visits (Singhal et al., 2011), increased risk of recurrent infections and antibiotic use (Jervis-Bardy and Wormald, 2012) as well as poorer postoperative progression (Foreman and Wormald, 2010; Singhal et al., 2010). Such biofilms are up to 1000 -fold more tolerant of current antibiotic therapies than their planktonic counterparts (Anwar et al., 1990). Further, increased levels of antibiotic resistance observed in pathogenic bacteria around the globe (Roca et al., 2015) also limit the success of antibiotic therapies. It is important that new therapies which effectively treat such infections are identified.

One alternative to antibiotics, originally described in the early 1900s and coming back into focus, is bacteriophage "phage" therapy (Carlton, 1999). Beneficially, phages are not only effective against planktonic infections, but can also infect and lyse biofilmbound cells (Doolittle et al., 1995; Corbin et al., 2001; Tait et al., 2002; Sillankorva et al., 2004; Curtin and Donlan, 2006; Cerca et al., 2007; Lu and Collins, 2007; Carson et al., 2010; Fu et al., 2010). Recently, we have shown that topical phage therapy has potential against pathogenic S. aureus bacterial biofilms, using an animal model of rhinosinusitis (Drilling et al., 2014a). Our previous work demonstrated the safety of oncedaily phage application into the frontal sinuses of sheep for 3 days (Drilling et al., 2014a). The first aim of the current work was to examine the safety of phage administration for a substantially longer period of time. In the current study we investigated the effects of a longer-term (20 day) application of twice-daily frontal sinus bacteriophage flushes in sheep. A cocktail of two phages against S. aureus, designated NOV012, was used. NOV012 contains two highly-characterized phages, K710 and P68. Both the parental version of phage K710, phage K (O'Flaherty et al., 2004), and phage P68 (Vybiral et al., 2003) have had their genomes completely sequenced, and they have been shown to lack any known genes that could increase the virulence of $S$. aureus or confer resistance to antibiotics (Vybiral et al., 2003; O'Flaherty et al., 2004). Phages K710 and P68 have been shown to be active against a wide range of $S$. aureus isolates from the United Kingdom and Europe (Takac and Blasi, 2005; J Clark, personal communication). The second aim of this work was to extend these observations by examining the susceptibility of local (Australian) S. aureus isolates to the phages in NOV012.

\section{METHODS}

\section{Bacteriophage}

A phage cocktail (NOV012) comprised of preparations of highly purified phages, K710 and P68, was obtained from Novolytics Pty. Ltd. (Warrington, United Kingdom). This cocktail of phages is functionally similar to the CTSA cocktail (Special Phage Services, Brookvale, NSW, Australia) which we used previously (Drilling et al., 2014a). For commercial reasons CTSA was unavailable. The concentration of phages in NOV012 stock was maintained at $1 \times 10^{8} \mathrm{PFU} / \mathrm{mL}$ for in vivo and in vitro work. To produce a heat-inactivated version of the cocktail, the phage stock was treated at $121^{\circ} \mathrm{C}$ for $15 \mathrm{~min}$ and tested by plaque assay to confirm complete inactivation prior to use.

\section{Bacteria}

Investigation of $S$. aureus strains isolated from CRS patients was approved by The Queen Elizabeth Hospital Human Ethics Committee. Written informed consent was obtained for all study participants. To isolate $S$. aureus from sinonasal swabs, Columbian blood agar plates, colistin nalidixic acid plates or cystine lactose electrolyte deficient plates (all from Thermofisher Scientific, Australia) were employed. Latex agglutination tests and antibiotic sensitivity testing were performed by the commercial laboratory Adelaide Pathology Partners and used to confirm identification of $S$. aureus and MRSA strains (data not shown). Antibiotic resistance was determined using disc diffusion methods as according to Clinical and Laboratory Standards Institute (CLSI) recommendations (CLSI, 2012). Isolates were then subcultured in nutrient broth overnight (Thermo Fisher, Scoresby, Victoria, Australia) and stored in nutrient broth with $20 \%$ glycerol at $-80^{\circ} \mathrm{C}$.

\section{CRS Bacterial Isolate Susceptibility to Phage Infection}

Bacterial sensitivity to phage infection was assessed by spotting phage onto bacterial lawns in an agar overlay system. Briefly, $S$. aureus isolates were cultured overnight at $37^{\circ} \mathrm{C}$ with shaking for 16-18 h in nutrient broth. Overnight cultures were diluted 1:30 in liquid $0.4 \%$ nutrient agar which was overlayed onto $1 \%$ nutrient agar. Dilutions of P68, K710, and the cocktail of these (NOV012) were spotted onto soft agar plates and allowed to dry. Plates were inverted and incubated overnight at $37^{\circ} \mathrm{C}$. Spots were assessed the next day and phage titres and plaque morphologies recorded. Plaques were ranked " +++ " (highly sensitive, clear plaque) through to "+" (slightly sensitive, plaque barely discernible), and plaques of status intermediate between these were ranked " ++ " (moderately sensitive). Results were termed "lysis from without" (LWO) when zones of inhibition were observed however discreet plaques were not evident when the assay used diluted phage stocks. Bacterial isolates were considered susceptible to phages if a plaque was discernible. To determine the strain type of the isolates, pulsed-field gel electrophoresis was used as described (O'Brien et al., 2006). Isolates with $\geq 80 \%$ similarity or $<6$ band differences were considered the same strain. Efficiency of plating was determined using the concentration of phage determined from infection of the S. aureus reference strain ATCC 25923 (Drilling et al., 2014a,b, 2016).

\section{Frontal Sinus Access and Treatment}

Animal work performed in this study was approved by the South Australian Health and Medical Research Institute and the University of Adelaide Animal Ethics Committees. Access to the ovine frontal sinus was achieved through the placement of mini-trephines, as described (Ha et al., 2007). Once accessed, sinuses where flushed twice daily with $50 \mathrm{~mL}$ of treatment using an extension cannula for 20 days. Sheep were treated with one of three different treatments: $0.9 \%$ saline ("CONT"), $0.9 \%$ saline containing $2 \times 10^{6} \mathrm{pfu} / \mathrm{mL}$ heat-inactivated phage 
NOV012 $(\mathrm{HI} p)$ or $0.9 \%$ saline containing $2 \times 10^{6} \mathrm{pfu} / \mathrm{mL}$ active NOV012 (NOV012). Each treatment group consisted of 4 sheep. One trephine from each treatment group became blocked during the treatment, resulting in $n=7$ sinuses per group. Sheep were monitored for general wellbeing during treatment. At the completion of treatment, sheep were euthanized and sinus tissue harvested for analysis. Microbiology swabs were taken to determine the bacterial composition of the sinus.

\section{Histology and Scanning Electron Microscopy}

Mucosal sections were dissected and placed in either $10 \%$ formalin for histological analysis, or scanning electron microscopy (SEM) buffer [4\% paraformaldehyde/1.25\% glutaraldehyde in phosphate-buffered solution (PBS) with $4 \%$ sucrose] for SEM. For histological analysis, tissue was embedded into paraffin blocks, sectioned, mounted on slides, and stained using haematoxylin and eosin (H\&E). Sections were examined by an experienced tissue pathologist (author CJ). Sections were identified only by a code to ensure the examining pathologist was unaware of which treatment had been provided to the animals. The examining pathologist graded the tissue for levels of inflammation, oedema, fibrosis, and presence or absence of goblet cell hyperplasia. For SEM, tissue was counterstained using $2 \%$ osmium tetroxide and dehydrated using a graded series of $70-100 \%$ ethanol washes. The tissue was chemically dried using hexamethyldisilazane (Sigma Aldrich) and mounted on SEM stub specimen mounts (Ted Pella, Redding, CA). The stubs were then coated in carbon using a standard carbon coater (Ted Pella) and viewed using an XL30 field emission Gun scanning electron microscope (Philips, Eindhoven, Netherlands). Five images of each tissue section were captured at magnification $2500 \times$ where at least $50 \%$ of the image allowed visualization of the tissue surface. Each image was broken down into $2 \mathrm{~cm}^{2}$ grid sections and scored either: 1 , full cilia coverage; 0.5 , some cilia coverage; 0 , no cilia present. Not counted, mucus covering cilia or epithelial layer, so tissue could not be visualized.

\section{Isolation of Phage from Serum Samples}

Serum samples were collected from all sheep prior to the first treatment flush. Further, sheep in the inactivated phage group and in the control group had serum samples taken on days 7 , 14 and 19 after the first flush. Phage-treated sheep had serum samples taken $10 \mathrm{~min}$, and 1, 2, and $4 \mathrm{~h}$ after flush 1 , and $18 \mathrm{~h}$ after the second flush. Serum samples were not found to contain phages at any of the tested time points. Therefore on days 7, 14, and 19, serum samples were harvested directly after phage flush 1 as well as 1 and $2 \mathrm{~h}$ post-flush 1 and $18 \mathrm{~h}$ post-flush 2 . A mucosal sample $(1 \mathrm{~g})$ harvested from each phage-treated sheep on day 21 was processed and filtered as previously described (Drilling et al., 2014a). All harvested serum and mucosal samples were tested for infectious phage using the agar overlay plaque assay method. Serum $(1 \mathrm{ml})$ or processed mucosal sample was mixed with cultures of S. aureus strain ATCC 25923 (cultured as above) and incubated at room temperature for $15 \mathrm{~min}$. Samples were then mixed with $2 \mathrm{~mL}$ of $0.7 \%$ nutrient agar and overlayed onto $1 \%$ nutrient agar plates. Plates were examined every $24 \mathrm{~h}$ for 3 days for the presence of plaques. Agar overlays were performed in triplicate.

\section{Statistics}

Statistical analyses were performed using SPSS version 23 software (IBM ${ }^{\circledR}$ SPSS ${ }^{\circledR}$ Statistics, New York, USA). Fisher's exact tests were used to compare the range of $S$. aureus stains that the phage preparations (P68 vs. K710 vs. cocktail) could infect and kill. All other statistical comparisons were performed using Kruskal-Wallis analysis and post-hoc with Bonferroni correction (Theodorsson-Norheim, 1986).

\section{RESULTS}

\section{Infection Range of Phages P68 and K710 Against CRS-Derived S. aureus Clinical Isolates}

S. aureus isolates from 61 patients diagnosed with CRS were examined (Table 1). When tested for strain type by pulse-field gel electrophoresis, 25 different strains were identified. Each strain contained 1-6 different clonal types. Clonal types R1, R3, and T3 were observed in the isolate population more twice. When tested for susceptibility to K710, P68, and NOV012, 36/61 isolates (59\%) were found sensitive to phage K710, $45(74 \%)$ were sensitive to P68, and $52(85 \%)$ were sensitive to NOV012 (Table 1). The cocktail was able to infect significantly more $S$. aureus strains compared to single K710 application $(p=0.0022)$. The cocktail lysed more strains compared to P68, however this was not statistically significant. Five CRS isolates were identified to be methicillin-resistant S. aureus (MRSA) isolates. Three of the five MRSA isolates were susceptible to K710 and all five MRSA isolates were susceptible to P68. Efficiency of plating for each isolate ranged from 0.002 to 4 -fold for K710, 2.7E-06 to 6.7-fold for P68 and 4E-06 to 8-fold for NOV012.

\section{Animal Studies}

\section{Observations of Sheep General Health}

During phage administration to sheep, there was no change in the general well-being of three out of four sheep in each of the control group and the phage group. One sheep in the control group and one in the phage group experienced some loss of appetite during the treatment period. Both sheep were found to have infections at the site of catheter insertion, which was thought to be the cause of appetite disruption. Antibiotic treatment during the treatment period, in accordance with the ethics committeeapproved experimentation protocol, improved the appetite of both sheep. The general health of all four sheep treated with HI $p$ was as expected and no change in sheep well-being was observed in this group.

\section{Histology of Sheep Sinus Mucosa}

$H \& E$ stained tissue sections taken from sheep euthanized at the end of the treatment period (Figure 1) were examined for inflammation, oedema, fibrosis and the presence or absence of goblet cell hyperplasia. There were no significant differences between the groups in regard to each of these parameters (data not shown). 
TABLE 1 | Sensitivity of S. aureus isolates of CRS origin to bacteriophage lysis (efficiency of plating indicated in brackets).

\begin{tabular}{|c|c|c|c|}
\hline Pulsotype & K710 & P68 & NOV012 \\
\hline $\mathrm{A} 1$ & LWO & LWO & LWO \\
\hline $\mathrm{A} 2$ & $+++(0.07)$ & $++(0.006)$ & $+++(0.3)$ \\
\hline A3 & $+(0.004)$ & $+(0.0003)$ & $+(0.003)$ \\
\hline B1 & $+++(0.7)$ & $+(0.0006)$ & $+++(0.5)$ \\
\hline B2 & LWO & $+++(0.2)$ & $+++(0.2)$ \\
\hline C1 & LWO & $++(0.0002)$ & $+(0.0003)$ \\
\hline C2 & $++(0.2)$ & $\mathrm{R}$ & $++(0.1)$ \\
\hline C3 & $+(0.02)$ & $\mathrm{R}$ & $+(0.02)$ \\
\hline C4 & $\mathrm{R}$ & $+(2.7 \mathrm{E}-06)$ & $+(4 \mathrm{E}-06)$ \\
\hline C5 & $+(0.002)$ & LWO & $+(0.004)$ \\
\hline C6 & $\mathrm{R}$ & $+(6 \mathrm{E}-06)$ & $+(4 \mathrm{E}-06)$ \\
\hline D1 & LWO & $\mathrm{R}$ & LWO \\
\hline D2 & $\mathrm{R}$ & $\mathrm{R}$ & $\mathrm{R}$ \\
\hline D3 & LWO & $+(0.003)$ & $+(0.9)$ \\
\hline D4 & LWO & $\mathrm{R}$ & LWO \\
\hline E & $+++(0.5)$ & $+++(0.26)$ & $+++(0.6)$ \\
\hline $\mathrm{F}$ & $+++(0.02)$ & $+++(0.19)$ & $+++(0.29)$ \\
\hline G & $+(0.007)$ & $\mathrm{R}$ & $+(0.008)$ \\
\hline $\mathrm{H} 1$ & LWO & LWO & LWO \\
\hline $\mathrm{H} 2$ & $\mathrm{R}$ & $+++(2)$ & $+++(3)$ \\
\hline H3 & $\mathrm{R}$ & $\mathrm{R}$ & $\mathrm{R}$ \\
\hline $\mathrm{H} 4$ & $+++(0.58)$ & $+++(3)$ & $+++(3)$ \\
\hline H5 & $+++(0.19)$ & $+++(0.02)$ & $+++(0.53)$ \\
\hline $\mathrm{H} 6$ & $+++(0.3)$ & $+++(1.1)$ & $+++(2)$ \\
\hline 11 & $+++(4)$ & $+++(2)$ & $+++(5)$ \\
\hline 12 & $+++(0.3)$ & $+++(0.03)$ & $+++(3)$ \\
\hline J & $+++(0.13)$ & $+++(4)$ & $+++(6)$ \\
\hline K & $+++(0.74)$ & $+++(0.04)$ & $+++(0.79)$ \\
\hline L & +++ & +++ & +++ \\
\hline M & +++ & LWO & +++ \\
\hline N1 & LWO & ++ & ++ \\
\hline N2 & $+++(0.25)$ & $++(0.9)$ & $+++(0.6)$ \\
\hline N3 & $+++(0.1)$ & $+++(0.5)$ & $+++(3)$ \\
\hline O1 & $+++(0.5)$ & $+++(1.3)$ & $+++(0.4)$ \\
\hline $\mathrm{O} 2$ & $+++(0.2)$ & $+(0.0006)$ & $+++(0.5)$ \\
\hline O3 & $+++(0.14)$ & $\mathrm{R}$ & $+++(0.16)$ \\
\hline$P$ & LWO & LWO & LWO \\
\hline Q & LWO & $+++(0.24)$ & $+++(0.14)$ \\
\hline R1 & $\mathrm{R}$ & $+++(4)$ & $+++(6)$ \\
\hline R1 & $\mathrm{R}$ & $++(0.15)$ & $++(0.2)$ \\
\hline $\mathrm{R} 2$ & $+++(0.09)$ & $+++(3.8)$ & $+++(2.7)$ \\
\hline R3 & $\mathrm{R}$ & $+++(5.3)$ & $+++(8)$ \\
\hline R3 & $\mathrm{R}$ & $+++(0.9)$ & $+++(1.1)$ \\
\hline R4 & $\mathrm{R}$ & $+++(2)$ & $+++(3)$ \\
\hline R5 & $+++(0.4)$ & $+++(2)$ & $+++(3.3)$ \\
\hline R6 & $+++(0.27)$ & $+++(2.7)$ & $+++(4)$ \\
\hline S1 & $++(0.05)$ & $+(0.0038)$ & $++(0.11)$ \\
\hline S2 & $+++(0.08)$ & $++(0.001)$ & $+++(0.4)$ \\
\hline $\mathrm{T} 1$ & LWO & $\mathrm{R}$ & LWO \\
\hline T2 & LWO & $+++(6.7)$ & $+++(5.3)$ \\
\hline
\end{tabular}

(Continued)
TABLE 1 | Continued

\begin{tabular}{llll}
\hline Pulsotype & K710 & P68 & Nov012 \\
\hline T3 & $+++(0.07)$ & $+++(0.47)$ & $+++(0.27)$ \\
T3 & $+++(0.04)$ & $+++(0.74)$ & $+++(0.79)$ \\
T4 & $+++(0.6)$ & $\mathrm{R}$ & $+++(1.2)$ \\
T5 & LWO & $+++(0.19)$ & $+++(0.53)$ \\
U & $+++(0.7)$ & $++(0.0006)$ & $+++(0.54)$ \\
V1 & $+++(0.27)$ & $+++(0.03)$ & $+++(0.25)$ \\
V1 & $+++(0.1)$ & $+++(0.4)$ & $+++(7.3)$ \\
W & LWO & $R$ & LWO \\
X & $+++(0.93)$ & $+++(0.09)$ & $+++(1.2)$ \\
Y1 & $+++(0.12)$ & $+++(0.02)$ & $+++(0.3)$ \\
Y2 & LWO & $+++(0.15)$ & $+++(1.13)$ \\
\hline
\end{tabular}

Showing lysis of S. aureus isolates distinguished on the basis of pulsed-field gel electrophoresis ("pulsotypes"). NOV012 lysed 52/61 (85\%) of isolates. LWO, lysis from without; $R$, resistant; +, slightly sensitive; ++, moderately sensitive; +++, highly sensitive. Gray shaded isolates represent MRSA strains. All strains where obtained from The Queen Elizabeth hospital, Woodville, Australia.

Presence and Appearance of Cilia of Mucosa Tissue

SEM was performed to allow closer inspection of sinus mucosa cilia. Cilia of all seven sinus samples harvested from HIp treatment were able to be visualized. The cilia of one control treated sheep sample and one phage treated sample were obscured from view by mucus, hence these samples were excluded from analysis. The appearance and coverage of the cilia was similar across the groups (Figure 2).

\section{Phage Detection in Sheep Serum}

Using plaque assays, no infectious phages were detected in serum of the CONT, Hip, or NOV012-treated sheep taken at any timepoint during the experiment.

\section{DISCUSSION}

Phage therapy has almost a 100 year history of human application for treating bacterial infections (Carlton, 1999). Accompanying this long history is an outstanding record of safety. There are numerous reports of the safety of phage therapy in animal (Soothill, 1994; Biswas et al., 2002; Wills et al., 2005; McVay et al., 2007; Hawkins et al., 2010; Park et al., 2014) and in human trials (Markoishvili et al., 2002; Bruttin and Brussow, 2005; Rhoads et al., 2009; Wright et al., 2009; Sarker et al., 2012; McCallin et al., 2013). Our previous work showed that shortterm bacteriophage application is safe when applied topically to the sheep sinonasal region (Drilling et al., 2014a). This study aimed to extend this work by assessing longer-term (20 days) sinonasal phage application. This safety data is needed to support the further preclinical development of phage therapy in general and NOVO12 specifically as it is likely that phage therapy would be used in patients for an extended period of time, at least 2 weeks.

It is recognized that phage may interact with some aspects of the host immune system, and it is important to ensure they do not elicit adverse immune responses (Kaur et al., 2012). Supporting 

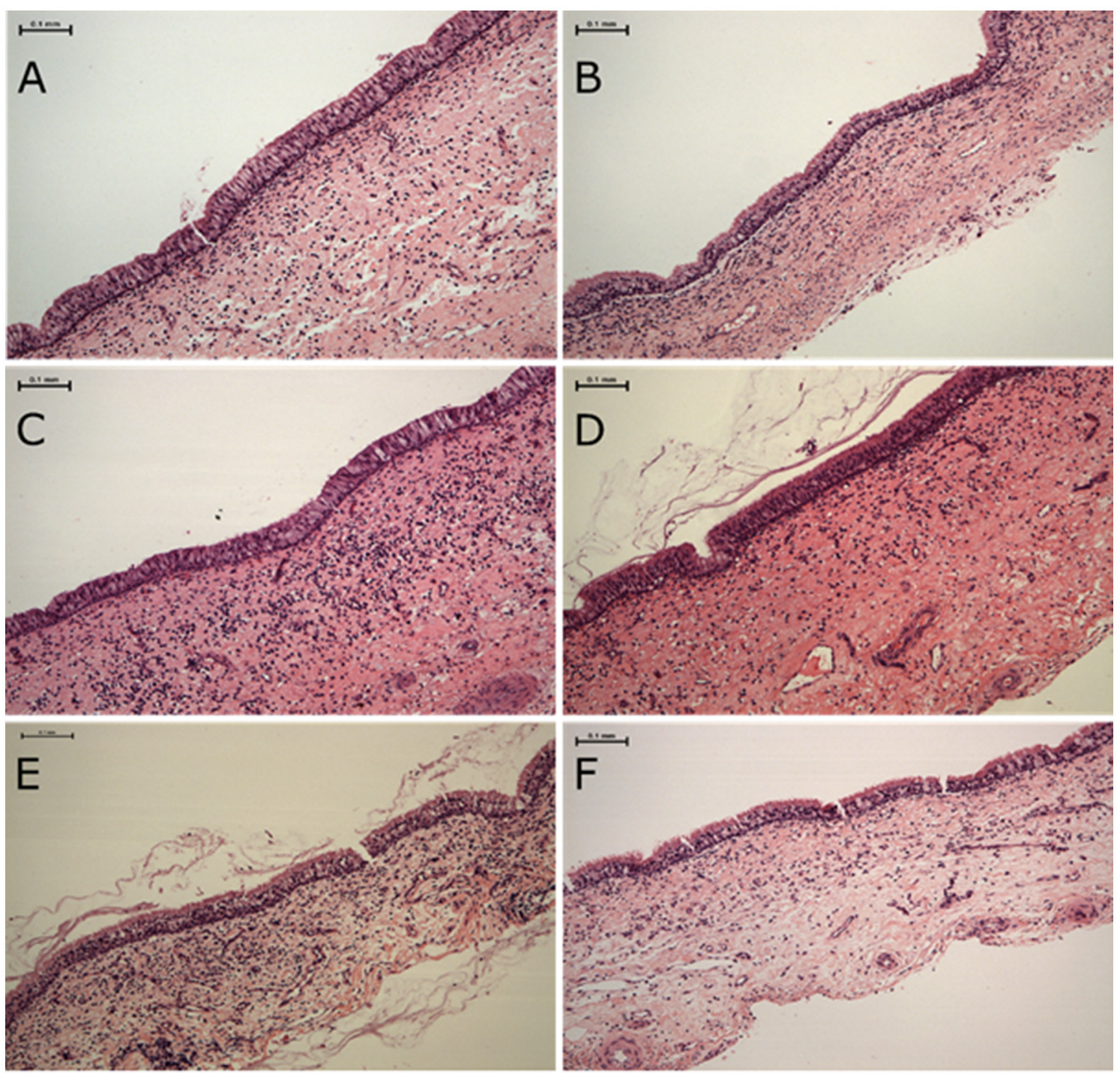

FIGURE 1 | Haematoxylin and eosin stained sheep nasal mucosa sections. Sections are of tissues taken from animals euthanized after 20 days of treatment as below. No differences in tissue inflammation, oedema, fibrosis and the presence or absence of goblet cell hyperplasia was observed between treatment groups (A,B) control, (C,D) heat-inactivated NOV012 (Hip) treatment and (E,F) active NOV012 treatment.

our previous work (Drilling et al., 2014a), this study shows that 20 days of topical phage therapy did not modify or damage the architecture of the sinus mucosal lining. Phage application for this extended period did not appear to increase or alter the profile of immune cells in the sinus mucosa. A limitation of this study is that only the presence of the cells was examined, whereas stimulation of the cells in relation to immune effector molecules such as cytokines was not investigated. Previous work has investigated this parameter, applying phage T4 or purified phage T4 proteins to mice and humans (Miernikiewicz et al., 2013). It was shown that such products did not stimulate the production of inflammatory related cytokines and reactive oxygen species (ROS; Miernikiewicz et al., 2013). In contrast, it has been suggested that through complex bacterial-phagehost interaction, phage can reduce ROS production (Przerwa et al., 2006; Miedzybrodzki et al., 2008). Recent research has also investigated the effect on phage infectivity when exposed to cell lines that mounted an inflammatory response to the phage. This study found that the phage still retained infectivity against bacterial cells (Khan Mirzaei et al., 2016).

It is not known whether phages can traverse the sinonasal mucosal barrier to gain access to the bloodstream. During the 20 days of treatment, no phages were detected in the bloodstream. A limitation of this study, which relied on plaque assays, is that it could not determine whether inactivated phage or phage genomes entered the bloodstream. A further limitation is that this study did not address the question of whether the sheep developed antibodies against phages. It has been shown that neutralizing antibodies may be produced following phage treatment (Kucharewicz-Krukowska and Slopek, 1987), 


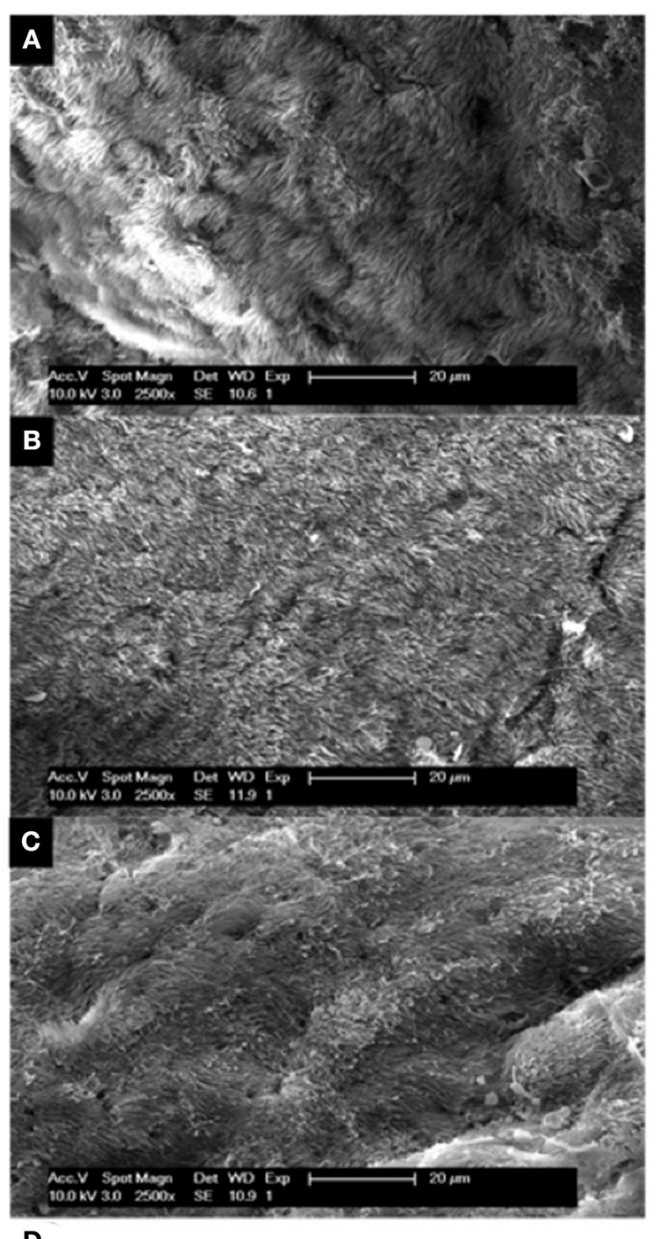

D

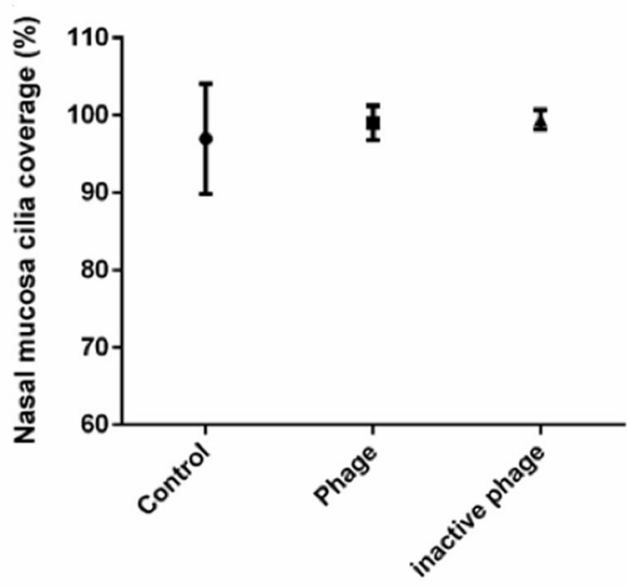

Treatment

FIGURE 2 | Representative images of sheep nasal mucosa viewed using scanning electron microscopy and analysis of cilia coverage. Cilia coverage and morphology were similar between all treatment groups including (A) control, (B) heat-inactivated NOV012 (Hip) treatment, and (C) active NOV012 treatment. (D) Five images of each tissue section were captured at $2500 \times$ magnification, divided into $2 \mathrm{~cm}^{2}$ grid sections and each grid scored according to 1 , full cilia coverage; 0.5 , some cilia coverage; 0 , no cilia present. This graph shows the average percentage coverage across the three treatment groups, no statistical difference was observed between the groups. and our future work will examine this possibility. This is of interest because it is not yet confirmed whether development of anti-phage antibodies will have a negative impact on phage therapy (Sulakvelidze et al., 2001). Recent research however has shown positive results, showing that development of antibodies may not necessarily strongly impact the clinical success of phage therapy (Zaczek et al., 2016; Lusiak-Szelachowska et al., 2017).

In addition to examining the safety profile of phage cocktail NOV012, this study also investigated the NOV012 host range in the context of CRS $S$. aureus infections. The findings of this study build on our previous work (Drilling et al., 2014a) that suggests using a cocktail of phage assisted in overcoming issues of matching phage to bacteria. We found that phage K710 was effective against $59 \%$ of the $S$. aureus strains in our panel of isolates, which was increased to $85 \%$ with addition of phage P68. Using cocktails rather than a single phage has the additional benefit of reducing the rate of generation of bacteria resistant to phage infection (Chan et al., 2013).

This work has implications beyond the treatment of CRS. For example, nasal colonization with $S$. aureus increases the risk of surgical wound infection (Perl and Roy, 1995). S. aureus decolonization reduces such risks (Bode et al., 2010; Chen et al., 2013), and phage have potential to achieve this. Other potential applications include topical treatment of burn wounds (Mousa, 2005) and treatment of indwelling catheter infections (Piraino, 2000). Importantly, this therapy can be broadened to target other bacterial pathogens.

\section{CONCLUSIONS}

This work confirms that the NOV012 phage cocktail infects a broad range of $S$. aureus isolates, including a number of MRSA isolates, from CRS patients. Further, we find that longer term (20 day) topical application of the cocktail is safe for sheep sinonasal application. This safety data supports the potential for the use of phage as a topical antimicrobial treatment in CRS and will help build the profile of the product to lead to the ability to use the product in clinical trials and eventually commercially.

\section{AUTHOR CONTRIBUTIONS}

AD executed experiments, wrote first draft. MO assisted with experiments, edited first draft. DM assisted with experiments. CJ assisted with data interpretation. PS and SV helped with experiment design, data interpretation, manuscript writing. JC helped with data interpretation. PW designed the study, manuscript writing.

\section{ACKNOWLEDGMENTS}

This project was funded by the Department of SurgeryOtolaryngology Head and Neck Surgery, The Queen Elizabeth Hospital, Woodville, South Australia, the University of Adelaide, Adelaide, South Australia, Australia and by a project grant to PW from The Hospital Research Foundation, South Australia, Australia. 


\section{REFERENCES}

Anwar, H., Dasgupta, M. K., and Costerton, J. W. (1990). Testing the susceptibility of bacteria in biofilms to antibacterial agents. Antimicrob. Agents Chemother. 34, 2043-2046. doi: 10.1128/AAC.34.11.2043

Baldoni, D., Haschke, M., Rajacic, Z., Zimmerli, W., and Trampuz, A. (2009). Linezolid alone or combined with rifampin against methicillin-resistant Staphylococcus aureus in experimental foreign-body infection. Antimicrob Agents Chemother. 53, 1142-1148. doi: 10.1128/AAC.00775-08

Biswas, B., Adhya, S., Washart, P., Paul, B., Trostel, A. N., Powell, B., et al. (2002). Bacteriophage therapy rescues mice bacteremic from a clinical isolate of vancomycin-resistant Enterococcus faecium. Infect. Immun. 70, 204-210. doi: 10.1128/IAI.70.1.204-210.2002

Bode, L. G., Kluytmans, J. A., Wertheim, H. F., Bogaers, D., VandenbrouckeGrauls, C. M., Roosendaal, R., et al. (2010). Preventing surgical-site infections in nasal carriers of Staphylococcus aureus. N. Engl. J. Med. 362, 9-17. doi: 10.1056/NEJMoa0808939

Bruttin, A., and Brussow, H. (2005). Human volunteers receiving Escherichia coli phage T4 orally: a safety test of phage therapy. Antimicrob. Agents Chemother. 49, 2874-2878. doi: 10.1128/AAC.49.7.2874-2878.2005

Carlton, R. M. (1999). Phage therapy: past history and future prospects. Arch. Immunol. Ther. Exp. 47, 267-274.

Carson, L., Gorman, S. P., and Gilmore, B. F. (2010). The use of lytic bacteriophages in the prevention and eradication of biofilms of Proteus mirabilis and Escherichia coli. FEMS Immunol. Med. Microbiol. 59, 447-455. doi: 10.1111/j.1574-695X.2010.00696.x

Cerca, N., Oliveira, R., and Azeredo, J. (2007). Susceptibility of Staphylococcus epidermidis planktonic cells and biofilms to the lytic action of staphylococcus bacteriophage K. Lett. Appl. Microbiol. 45, 313-317. doi: 10.1111/j.1472-765X.2007.02190.x

Chan, B. K., Abedon, S. T., and Loc-Carrillo, C. (2013). Phage cocktails and the future of phage therapy. Future Microbiol. 8, 769-783. doi: 10.2217/fmb.13.47

Chen, A. F., Wessel, C. B., and Rao, N. (2013). Staphylococcus aureus screening and decolonization in orthopaedic surgery and reduction of surgical site infections. Clin. Orthop. Relat. Res. 471, 2383-2399. doi: 10.1007/s11999-0132875-0

CLSI (2012). Performance Standards for Antimicrobial Disk Susceptibility Tests; Approved Standard. M02-A11, Vol. 32. Wayne: Clinical and Laboratory Standards Institute.

Corbin, B. D., McLean, R. J., and Aron, G. M. (2001). Bacteriophage T4 multiplication in a glucose-limited Escherichia coli biofilm. Can. J. Microbiol. 47, 680-684. doi: 10.1139/cjm-47-7-680

Curtin, J. J., and Donlan, R. M. (2006). Using bacteriophages to reduce formation of catheter-associated biofilms by Staphylococcus epidermidis. Antimicrob. Agents Chemother. 50, 1268-1275. doi: 10.1128/AAC.50.4.1268-1275.2006

Doolittle, M. M., Cooney, J. J., and Caldwell, D. E. (1995). Lytic infection of Escherichia coli biofilms by bacteriophage T4. Can. J. Microbiol. 41, 12-18. doi: 10.1139/m95-002

Drilling, A. J., Cooksley, C., Chan, C., Wormald, P. J., and Vreugde, S. (2016). Fighting sinus-derived Staphylococcus aureus biofilms in vitro with a bacteriophage-derived muralytic enzyme. Int. Forum Allergy Rhinol. 6, 349-355. doi: 10.1002/alr.21680

Drilling, A., Morales, S., Boase, S., Jervis-Bardy, J., James, C., Jardeleza, C., et al. (2014a). Safety and efficacy of topical bacteriophage and ethylenediaminetetraacetic acid treatment of Staphylococcus aureus infection in a sheep model of sinusitis. Int. Forum Allergy Rhinol. 4, 176-186. doi: 10.1002/alr.21270

Drilling, A., Morales, S., Jardeleza, C., Vreugde, S., Speck, P., and Wormald, P. J. (2014b). Bacteriophage reduces biofilm of Staphylococcus aureus ex vivo isolates from chronic rhinosinusitis patients. Am. J. Rhinol. Allergy 28, 3-11. doi: 10.2500/ajra.2014.28.4001

Foreman, A., and Wormald, P. J. (2010). Different biofilms, different disease? a clinical outcomes study. Laryngoscope 120, 1701-1706. doi: 10.1002/lary.21024

Fu, W., Forster, T., Mayer, O., Curtin, J. J., Lehman, S. M., and Donlan, R. M. (2010). Bacteriophage cocktail for the prevention of biofilm formation by Pseudomonas aeruginosa on catheters in an in vitro model system. Antimicrob. Agents Chemother. 54, 397-404. doi: 10.1128/AAC.00669-09
Ha, K. R., Psaltis, A. J., Tan, L., and Wormald, P. J. (2007). A sheep model for the study of biofilms in rhinosinusitis. Am. J. Rhinol. 21, 339-345. doi: 10.2500/ajr.2007.21.3032

Hawkins, C., Harper, D., Burch, D., Anggard, E., and Soothill, J. (2010). Topical treatment of Pseudomonas aeruginosa otitis of dogs with a bacteriophage mixture: a before/after clinical trial. Vet. Microbiol. 146, 309-313. doi: 10.1016/j.vetmic.2010.05.014

Jervis-Bardy, J., and Wormald, P. J. (2012). Microbiological outcomes following mupirocin nasal washes for symptomatic, Staphylococcus aureus-positive chronic rhinosinusitis following endoscopic sinus surgery. Int. Forum Allergy Rhinol. 2, 111-115. doi: 10.1002/alr.20106

Kaur, T., Nafissi, N., Wasfi, O., Sheldon, K., Wettig, S., and Slavcev, R. (2012). Immunocompatibility of bacteriophages as nanomedicines. J. Nanotechnol. 2012:247427. doi: 10.1155/2012/247427

Khan Mirzaei, M., Haileselassie, Y., Navis, M., Cooper, C., Sverremark-Ekstrom, E., and Nilsson, A. S. (2016). Morphologically distinct Escherichia coli bacteriophages differ in their efficacy and ability to stimulate cytokine release In vitro. Front. Microbiol. 7:437. doi: 10.3389/fmicb.2016.00437

Kucharewicz-Krukowska, A., and Slopek, S. (1987). Immunogenic effect of bacteriophage in patients subjected to phage therapy. Arch. Immunol. Ther. Exp. 35, 553-561.

Lu, T. K., and Collins, J. J. (2007). Dispersing biofilms with engineered enzymatic bacteriophage. Proc. Natl. Acad. Sci. U.S.A. 104, 11197-11202. doi: 10.1073/pnas.0704624104

Lusiak-Szelachowska, M., Zaczek, M., Weber-Dabrowska, B., Miedzybrodzki, R., Letkiewicz, S., Fortuna, W., et al. (2017). Antiphage activity of sera during phage therapy in relation to its outcome. Future Microbial. 12, 109-117. doi: 10.2217/fmb-2016-0156

Markoishvili, K., Tsitlanadze, G., Katsarava, R., Morris, J. G. Jr., and Sulakvelidze, A. (2002). A novel sustained-release matrix based on biodegradable poly(ester amide)s and impregnated with bacteriophages and an antibiotic shows promise in management of infected venous stasis ulcers and other poorly healing wounds. Int. J. Dermatol. 41, 453-458. doi: 10.1046/j.1365-4362.2002.01451.x

McCallin, S., Alam Sarker, S., Barretto, C., Sultana, S., Berger, B., Huq, S., et al. (2013). Safety analysis of a Russian phage cocktail: from MetaGenomic analysis to oral application in healthy human subjects. Virology 443, 187-196. doi: 10.1016/j.virol.2013.05.022

McVay, C. S., Velasquez, M., and Fralick, J. A. (2007). Phage therapy of Pseudomonas aeruginosa infection in a mouse burn wound model. Antimicrob. Agents Chemother. 51, 1934-1938. doi: 10.1128/AAC.01028-06

Miedzybrodzki, R., Switala-Jelen, K., Fortuna, W., Weber-Dabrowska, B., Przerwa, A., Lusiak-Szelachowska, M., et al. (2008). Bacteriophage preparation inhibition of reactive oxygen species generation by endotoxinstimulated polymorphonuclear leukocytes. Virus Res. 131, 233-242. doi: 10.1016/j.virusres.2007.09.013

Miernikiewicz, P., Dabrowska, K., Piotrowicz, A., Owczarek, B., Wojas-Turek, J., Kicielinska, J., et al. (2013). T4 phage and its head surface proteins do not stimulate inflammatory mediator production. PLOS ONE 8:e71036. doi: 10.1371/journal.pone.0071036

Mousa, H. A. (2005). Burn and scald injuries. East. Mediterr. Health J. 11, 1099-1109.

O’Brien, F. G., Udo, E. E., and Grubb, W. B. (2006). Contour-clamped homogeneous electric field electrophoresis of Staphylococcus aureus. Nature protoc. 1, 3028-3033. doi: 10.1038/nprot.2006.382

O'Flaherty, S., Coffey, A., Edwards, R., Meaney, W., Fitzgerald, G. F., and Ross, R. P. (2004). Genome of Staphylococcal phage K: a new lineage of Myoviridae infecting gram-positive bacteria with a low G+C content. J. Bacteriol. 186, 2862-2871. doi: 10.1128/JB.186.9.2862-2871.2004

Park, K., Cha, K. E., and Myung, H. (2014). Observation of inflammatory responses in mice orally fed with bacteriophage T7. J. Appl. Microbiol. 117, 627-633. doi: $10.1111 /$ jam. 12565

Perl, T. M., and Roy, M. C. (1995). Postoperative wound infections: risk factors and role of Staphylococcus aureus nasal carriage. J. Chemother. 7(Suppl. 3), 29-35.

Petti, C. A., Fowler, V. G. Jr. (2003). Staphylococcus aureus bacteremia and endocarditis. Cardiol. Clin. 21, 219-233.

Piraino, B. (2000). Staphylococcus aureus infections in dialysis patients: focus on prevention. ASAIO J. 46, S13-S17. doi: 10.1097/00002480-200011000-00031 
Przerwa, A., Zimecki, M., Switala-Jelen, K., Dabrowska, K., Krawczyk, E., Luczak, M., et al. (2006). Effects of bacteriophages on free radical production and phagocytic functions. Med. Microbiol. Immun. 195, 143-150. doi: 10.1007/s00430-006-0011-4

Rhoads, D. D., Wolcott, R. D., Kuskowski, M. A., Wolcott, B. M., Ward, L. S., and Sulakvelidze, A. (2009). Bacteriophage therapy of venous leg ulcers in humans: results of a phase I safety trial. J. Wound Care 18, 237-238, 240-233. doi: 10.12968/jowc.2009.18.6.42801

Roca, I., Akova, M., Baquero, F., Carlet, J., Cavaleri, M., Coenen, S., et al. (2015). The global threat of antimicrobial resistance: science for intervention. $N$. Microbes N. Infect. 6, 22-29. doi: 10.1016/j.nmni.2015.02.007

Sarker, S. A., McCallin, S., Barretto, C., Berger, B., Pittet, A. C., Sultana, S., et al. (2012). Oral T4-like phage cocktail application to healthy adult volunteers from Bangladesh. Virology 434, 222-232. doi: 10.1016/j.virol.2012.09.002

Sillankorva, S., Oliveira, R., Vieira, M. J., Sutherland, I. W., and Azeredo, J. (2004). Bacteriophage Phi S1 infection of Pseudomonas fluorescens planktonic cells versus biofilms. Biofouling 20, 133-138. doi: 10.1080/08927010410001723834

Singhal, D., Foreman, A., Bardy, J. J., and Wormald, P. (2011). J. Staphylococcus aureus biofilms: nemesis of endoscopic sinus surgery. Laryngoscope 121, 1578-1583. doi: 10.1002/lary.21805

Singhal, D., Psaltis, A. J., Foreman, A., and Wormald, P. J. (2010). The impact of biofilms on outcomes after endoscopic sinus surgery. Am. J. Rhinol. Allergy 24, 169-174. doi: 10.2500/ajra.2010.24.3462

Soothill, J. S. (1994). Bacteriophage prevents destruction of skin grafts by Pseudomonas aeruginosa. Burns 20, 209-211. doi: 10.1016/0305-4179(94)90184-8

Sulakvelidze, A., Alavidze, Z., and Morris, J. G. Jr. (2001). Bacteriophage therapy. Antimicrob. Agents Chemother. 45, 649-659. doi: 10.1128/AAC.45.3.649-659.2001

Tait, K., Skillman, L. C., and Sutherland, I. W. (2002). The efficacy of bacteriophage as a method of biofilm eradication. Biofouling 18, 305-311. doi: 10.1080/0892701021000034418

Takac, M., and Blasi, U. (2005). Phage P68 virion-associated protein 17 displays activity against clinical isolates of Staphylococcus aureus. Antimicrob. Agents Chemother. 49, 2934-2940. doi: 10.1128/AAC.49.7.2934-2940.2005

Theodorsson-Norheim, E. (1986). Kruskal-Wallis test: BASIC computer program to perform nonparametric one-way analysis of variance and multiple comparisons on ranks of several independent samples. Comput. Methods Programs Biomed 23, 57-62. doi: 10.1016/0169-2607(86)90081-7

Vybiral, D., Takac, M., Loessner, M., Witte, A., von Ahsen, U., and Blasi, U. (2003). Complete nucleotide sequence and molecular characterization of two lytic Staphylococcus aureus phages: 44AHJD and P68. FEMS Microbiol. Lett. 219, 275-283. doi: 10.1016/S0378-1097(03)00028-4

Wills, Q. F., Kerrigan, C., and Soothill, J. S. (2005). Experimental bacteriophage protection against Staphylococcus aureus abscesses in a rabbit model. Antimicrob. Agents Chemother. 49, 1220-1221. doi: 10.1128/AAC.49.3.1220-1221.2005

Wright, A., Hawkins, C. H., Anggard, E. E., and Harper, D. R. (2009). A controlled clinical trial of a therapeutic bacteriophage preparation in chronic otitis due to antibiotic-resistant Pseudomonas aeruginosa; a preliminary report of efficacy. Clin. Otolaryngol. 34, 349-357. doi: 10.1111/j.1749-4486.2009. 01973.x

Zaczek, M., Lusiak-Szelachowska, M., Jonczyk-Matysiak, E., Weber-Dabrowska, B., Miedzybrodzki, R., Owczarek, B., et al. (2016). Antibody production in response to staphylococcal ms-1 phage cocktail in patients undergoing phage therapy. Front. Microbiol. 7:1681. doi: 10.3389/fmicb.2016.01681

Ziran, B. H. (2007). Osteomyelitis. J. Trauma. 62 (6 Suppl.), S59-S60. doi: 10.1097/TA.0b013e318065abbd

Conflict of Interest Statement: JC is the Chief Scientific Officer of Fixed Phage Limited and provided PW with the phage used in this study. PW is a consultant for Neilmed.

The other authors declare that the research was conducted in the absence of any commercial or financial relationships that could be construed as a potential conflict of interest.

Copyright (c) 2017 Drilling, Ooi, Miljkovic, James, Speck, Vreugde, Clark and Wormald. This is an open-access article distributed under the terms of the Creative Commons Attribution License (CC BY). The use, distribution or reproduction in other forums is permitted, provided the original author(s) or licensor are credited and that the original publication in this journal is cited, in accordance with accepted academic practice. No use, distribution or reproduction is permitted which does not comply with these terms. 